do Departamento de Urbanismo da

Universidade de Brasília, com trabalhos de

pesquisa notadamente na área de habitação,

questões pertinentes ao solo urbano e aos

assentamentos urbanos-rurais, no Brasil.

\title{
Proposições sobre o objeto e o método do planejamento urbano
}

A produção escrita e a experiência acumulada nas atividades do planejamento urbano já permitem, ou estão a exigir, uma revisão, notadamente partindo-se de preocupações com seu grau de eficácia diante dos problemas concretos do desenvolvimento urbano brasileiro.

Nos últimos 20 anos, foram gastos muitos recursos em estudos e planos e a produção de consultores e pesquisadores é significativa. Entretanto - e este talvez seja o indicador mais nítido de que há problemas - muito pouco das proposições teóricas e práticas que essa produção oferece chega às vias da implementação efetiva, no quadro concreto do processo de desenvolvimento do espaço habitado do país.

A realidade frustrada, difícil e, na maior parte do território, inexistente do planejamento urbano tem sido justificada usualmente pelas friccões da natureza político-institucional, técnica e financeira que tais proposições têm que enfrentar em seu caminho, desde sua formulação nos gabinetes dos planejadores até a prática dodia-a-dia de sua implementação no quadro de nossas cidades. Tais dificuldades, aparentemente, são bastantes para explicar o panorama defasado entre a quantidade e a qualidade da produção de gabinete e uma prática eficaz.

Há contudo outras questões de caráter conceitual e metodológico que são também pertinentes às dificuldades da implantação eficaz do planejamento urbano. Elas são importantes e explicariam a ineficácia mesmo sem a presença das fricções.

O planejamento urbano vem se manifestando como uma prática eivada de empirismo e subjetivis- mo, com uma produção de propostas estanques no espaço e no tempo, submetido ao vício racionalista da supervalorização do chamado 'uso do solo', além do ranço acadêmico de ser resguardado aos gabinetes dos 'cientistas urbanos'. Na realidade, seus diagnósticos e suas proposições, como um todo, denotam uma prática carente da definição de seu próprio objeto teórico. Por isso os diagnósticos são puras descrições das manifestações aparentes da organização do espaço habitado e os objetivos do planejamento desse espaço são estabelecidos a priori de qualquer referência teórica, de forma idealista: as atividades poluidoras devem estar separadas das habitações, toda a cidade deve ter rede de distribuição de água potável, os equipamentos escolares devem ser accessíveis por caminhamento a pé, etc.

O planejamento urbano, entendido como uma intervenção sobre as tendências da desqualificação geral e específica do quadro físico-espacial habitado, tem uma validade intimamente associada à sua capacidade de mudança das realidades sócioespaciais. Sua eficácia depende, portanto, de duas condições: primeiro, o nível de conhecimento daquelas realidades; em segundo lugar, o poder desse conhecimento como matéria de pressão.

Quando se aceita que o planejamento exisțe para oferecer propostas ao processo decisório local, subentende-se a presença de uma ação política inerente que será tanto mais eficaz quanto mais comprometida com o conhecimento da realidade. Mas, que tipo de conhecimento é esse?

O primeiro equívoco presente nos processos usuais de conhecimento dos problemas urbanos consiste em pretender analisá-los apenas mediante 
sua decomposição em variáveis, quase sempre quantificadas estatísticamente e até elaboradas por algumas relações matemáticas ou somente interpretadas de maneira empírica e subjetiva, nas busca de 'causas', pretendendo que uma ação sobre estas possa objetivar a solução dos problemas detectados.

Comparece aqui uma questão de método. 0 conhecimento exigido para uma intervenção eficiente e correta sobre um determinado objeto, visando alterar seu processo de desenvolvimento, é o conhecimento científico, isto é, aquele que dá a conhecer a essência do objeto, as leis de seu movimento e, principalmente, as condicões sob as quais elas atuam. Somente esse tipo de conhecimento permite fazer previsões e somente planejam-se intervencões corretas quando se pode prever o comportamento, sob condições distintas e alternativas, de determinado fenômeno.

No caso de ação do planejamento urbano, seu objeto é ainda bastante desconhecido ao nível do conhecimento teórico, ou seja, do conhecimento que permite fazer previsões.

O fenômeno urbano é um objeto complexo em permanente movimento (cresscimento, expansão, transformação, segregação, etc.) de múltiplas manifestações e de múltiplas implicações. Partindo-se dessas manifestações o planejador precisa descobrir, ou melhor, definir, elucidar o problema da cidade em seu movimento de transformação permanente. Essa formulação vai além da simples descrição ou elaboração estatística. Ela busca a explicação do movimento da evolução urbana, para localizar por intermédio desse movimento o objeto real do planejamento urbano. Tal formulação realiza-se mediante a análise do movimento concreto de cada cidade e da busca de uma síntese explicativa para seu desenvolvimento.

Somente a partir dessa formulação é que se torna possivel a definição dos objetivos da ação planejadora. Os objetivos constituem-se em ações viáveis referentes e destinadas a mudar o movimento concreto da evolução urbana em suas tendências indesejadas. Essa intervenção prática estará, assim, garantida por um método científico que dirige a ação do planejador desde a definição do problema concreto até a formulação de propostas para o seu tratamento.

Provavelmente a ausência do exercício do método do conhecimento científico explique o segundo equívoco da prática do planejamento urbano que adotou o chamado 'uso do solo' como objeto de intervenção. Os 'planos de uso do solo', através de zoneamentos funcionais e de intensidade de oculpação e até das tipologias arquitetônicas, viabilizam por sua vez as propostas da infra-estrutura de saneamento, energia e comunicação e a distribuição dos equipamentos e dos locais de consumo coletivo. Ao mesmo tempo a legislação sobre o 'uso do solo' vem sendo revisada e são ensaiados esquemas variados para o chamado 'controle do uso do solo'.

A importância do solo urbano na produção da cidade é evidente. A investigação, porém, tem que objetivar o conhecimento dessa produção. Por meio dela o solo, sem perder importância, explica-se em seu papel essencial, não mais como o objeto do planejamento, mas enquanto componente importante do processo de produção e reprodução do quadro físico-espacial habitado. Na realidade, quando se trata de levantar problemas desse quadro, as manifestações evidentes são aquelas pertinentes ao seu uso - poluição, congestionamento, dificuldades de acesso, carência de equipamentos etc. Esse uso é o do espaço produzido, do espaço edificado, do 'espaço produto'; e um produto só se explica mediante seu processo de produção. Por isso, da análise do processo de produção do quadro habitado, podem emergir alguns níveis de explicação que darão a verdadeira dimensão e o verdadeiro papel ao componente solo, no quadro das relações presentes no processo geral de produção do quadro habitado.

Admite-se, pois, que as tendências de desqualificação desse quadro, percebidas no seu uso, são realmente determinadas e, conseqüentemente, explicadas no processo de produção de seus elementos construídos, todos eles produzidos e distribuídos segundo as leis do mercado capitalista e, por meio delas, concretizando o processo de crescimento e da transformação permanente dos espaços habitados.

Esse processo tem apresentado algumas regularidades que variam somente no grau de intensidade ou nas formas específicas que tomam em cada cidade: a) a expansão urbana concretiza-se mediante parcelamentos periféricos de baixa densidade, deixando vazios entre eles e a mancha urbana anterior; b) a demanda por habitação representa uma pressão cada vez mais forte e expressa-se por dificuldades de solvência frente a oferta; c) o espaço habitado apresenta um processo permanentemente de substituição de uso ou funcões, de edificaç̃es e de infra-estrutura urbana, sempre tendentes a uma divisão cada vez mais nítida do espaço social; d) há uma constante dificuldade para a produção e distribuição dos componentes da infra-estrutura urbana, dos equipamentos e dos serviços de uso coletivo.

Todo esse conjunto expressa um processo de produção do quadro habitado, que se apresenta como um produto distribuído de forma não equânime e cujas diferenças teriam forte implicação locacional. A rigor, é essa implicação locacional, quando analisada, que vai explicitar e explicar o papel do solo na- 
quele processo e permitirá inferir o tipo de intervenção realmente necessária e viável sobre esse componente, dentro do contexto do objeto real do planejamento urbano - que é o processo de produção (reprodução e distribuição) do quadro habitado.

Algumas importantes investigações já chegaram a conclusões sobre as determinações dos mecanismos da 'renda da situação' dada pela implicação locacional sobre a forma concreta com que se desenvolve e evolui o quadro habitado das cidades. As potencialidades dadas à realização de lucros extraordinários diferentes, em determinadas localizações urbanas, são a fonte de 'renda da situação' e determinam os preços dos terrenos (e conseqüentemente dos imóveis nele edificados). Com o crescimento da cidade, essas rendas alteram-se mais ou menos, suscitando a partir de um determinado limite a substituição do imóvel edificado. Assim, o zoneamento urbano é sobreditado pelo mecanismo da 'renda de situação', que passa a ser entendido como o operador econômico da estratificacão e da segregação do espaço habitado, por meio da relação que se estabelece entre as rendas e os salários da população e o movimento da valorização dos imóveis edificados. A medida que a cidade apresenta maiores taxas de crescimento, as curvas do aumento de ambos se afastam cada vez mais, favorecendo a segregação das populações pobres nas áreas desqualificadas da cidade e incentivando, por intermédio de pressão do déficit habitacional, os preços de monopólio no mercado imobiliário.

Por essa via explica-se como o 'uso do solo' planejado - em sua relação com a produção e reprodução do quadro habitado - poderá restabelecer algumas condiç̃es para a minimizaç̃o do mecanismo da 'renda de situação': seja por alteracões de intensidades do uso do solo; seja pela distribuição de áreas de lazer; seja por restrições legais e tributárias aos terrenos etc.

Entretanto, fica evidente que a 'renda de situação' somente se realiza por intermédio da produção de componentes do quadro construído e, portanto, todas as recomendaç̃es para seu controle têm conotaç̃es e componentes comuns aos demais meios da produção e distribuição das edificações e da infraestrutura urbana: a forma de distribuição das redes de água, esgoto, eletricidade e comunicações (vias e transportes, incluídos); e, além disso, as condições dadas ao desenvolvimento da alta de aluguéis e às taxações sobre o lucro imobiliário em geral.

Admitida a validade dessa definição do objeto, ela mostra como se inferem, com clareza, os elementos que devem sofrer a intervenção do planejamento, ou seja, induz a um processo de inferência dos objetivos da ação. Por exemplo, um objetivo geral inferido seria a minimização das rendas de situa- ção em sua dimensão absoluta e diferencial com a intenção de diminuir as pressões da demanda habitacional, por um lado, e desacelerar os processos de segregação residencial, por outro.

Um terceiro equivoco sobre o objeto do planejamento urbano refere-se ao seu âmbito, marca damente no sentido de duvidar se ele pode ser ape nas delimitado ou adstrito aos perímetros urbanos.

O problema dos assentamentos humanos, se se encara este como objeto da preocupação dos planejadores do espaço habitado, é bastante mais amplo do que o do espaço urbano. Quando se tem a oportunidade de investigar a respeito de áreas mais distantes das metrópoles, torna-se mais nítida a interação efetiva entre os assentamentos ditos rurais e os assentamentos urbanos, ao ponto de, contraditoriamente, tornar-se confusa a delimitação entre a natureza urbana e/ou rural de cada assentamento. Se os critérios adotados para diferenciar assentamentos urbano e rural forem tamanho, nivel de densificação da população ou função do assentamento, o tipo de atividade rural de expressiva parte da população urbana dificultaria o problema para uma delimitação precisa entre o que é urbano ou o que é rural. Em especial, quando se trata do espaço brasileiro, cuja evolução vem-se definindo, nos últimos 25 anos, pela permanente expansão de novas áreas para a produção agrícola e uma conseqüente transformação da estrutura territorial (em todo o Centro-Oeste e a Amazônia notadamente).

Cerca de $50 \%$ da população dessas regiões se distribui nos assentamentos ditos rurais, quase sempre sobreditados, em sua organização físico-espacial, pelos tipos e niveis de relação de trabalho presentes em cada microrregião: acampamentos de 'bóias-frias', onde se alojam durante a semana grupos de trabalhadores temporários; alojamento nas sedes de fazendas, onde se instalam por determinado tempo o trabalhador rural sem terra e sua familia; retiros isolados, ou em pequenos grupos, dos encarregados de certos setores de fazendas; pequenos nucleamentos (vilas e povoados), assentamentos de trabalhadores, com trabalho sazonal em determinada microrregião; conjuntos residenciais de agroindústrias, onde se acomodam os trabalhadores e suas famílias; assentamentos de grupos de posseiros (patrimônios); sedes de colonização oficial ou de empresas de colonização (muitas delas, em Rondônia, já se transformaram em sede de municípios); nucleamentos temporários de garimpeiros; assentamentos isolados de arrendatários, posseiros e meeiros; e mais recentemente os assentamentos dos Núcleos Urbanos de Apoio rural (NUAR) na área dos PDRI em Rondônia.

A estes assentamentos associa-se um conjunto de pequenas cidades entre setecentos a $100 \mathrm{mil}$ 
habitantes, geralmente em processo muito acelerado de crescimento e que, independente do tamanho, podem ser classificadas como: sedes regionais de prestação de serviços, com a periferia rural já quase toda estruturada em latifúndios e com periferia urbana que serve de assentamento a trabalhadores rurais; pequenas cidades satélites em geral em torno das capitais de estado, abrigando uma população que trabalha na capital, ou na cidade pólo microrregional; pequenas cidades com função microrregional importante como apoio à produção rural local, iriclusive abrigando grandes contingentes de trabaIhadores rurais sem terra, em péssimas condiç̃es de habitação; núcleos urbanos periféricos estagnados, em geral em áreas de minifúndio, apresentando indicadores de assumirem o papel de sede temporária dos fluxos migratórios regionais.

Todo esse conjunto de assentamentos está evidentemente relacionado, em sua forma e nível habitacional, ao estágio em que se encontra a organização da produção, principalmente nas áreas rurais. A característica de extrema mobilidade que rege a transformação desse conjunto urbano-rural apresenta, em cada microrregião, características diferentes segundo sua localização emáreas de fronteira agrícola ou em microrregiões de ocupação tradicional cujos processos de remembramento das pequenas e médias propriedades rurais tendem a uma estrutura latifundiária, para a implantação da pecuária de corte.

Cada manifestação das deficiências desse espaço habitado é específica e local. Todavia, ao menor exame, evidencia-se uma transcendência do espaço local, em sua interdependência com o quadro geral. Os espaços habitados são sempre uma função das formas de estruturação da produção nas áreas rurais.

$\mathrm{Na}$ realidade, pode-se afirmar que o problema urbano brasileiro multiplica-se dentro e mediante o crescimento das cidades e da transformação do campo, 'concomitantemente', não como uma questão de causa e efeito, mas como componente de um sistema único de relações.

Uma pesquisa realizada recentemente na área da região geo-econômica de Brasília, onde comparecem todos os tipos de assentamentos anteriormente descritos e todos os estágios da evolução de fronteira agrícola, permitiu descrever com clareza a relação constante e determinada do urbano e do rural. Nessa região o processo de esvaziamento do campo e a urbanização violenta, no período 1970-1980, está intimamente relacionado aos numerosos e constantes remembramentos da estrutura fundiária local, associados a formas de investimentos e exploração do setor primário que evoluem dos desmatamentos para as lavouras de arroz às pasta- gens artificiais para criação de gado de corte, principalmente. Nessa evolução desaparecem os pequenos estabelecimentos com a exclusão dos sistemas de meia e parceria e comparece a figura do trabaIhador assalariado no campo, cujas condições de trabalho quase sempre determinam a busca de um assentamento residencial alternativo entre os povoados próximos, as faixas de domínio das estradas ou a periferia das cidades.

A estabilidade nesses assentamentos, por sua vez, depende da oferta de trabalho e das condições de emprego das áreas rurais em processo de evolução e nas áreas urbanas mais acessíveis. Entretanto, esse fenômeno não está ocorrendo da mesma forma em toda a região. Há microrregiões como as do sudeste goiano e a do Mato Grosso de Goiás, onde, aparentemente, a urbanização dos trabalhadores do campo já ocorreu. Há outras onde este processo é mais recente, como nas microrregiões da Chapada dos Veadeiros, vão do Paraná e Serra Geral, que ainda apresentam, ao lado de taxas muito altas de crescimento urbano, indicadores de crescimento da população rural. Contudo, uma análise mais criteriosa permite verificar algumas características mais específicas desse processo geral que poderão esclarecer melhor o entendimento dos assentamentos da população em toda a região e suas tendências, mantidas as atuais condições de seu processo de desenvolvimento econômico.

Em todas as microrregiões, mesmo em está gios muito diferentes da evolução da ocupação rural e urbana, constata-se quatro regularidades presentes: 1.) os remembramentos iniciam-se no município da sede urbana mais importante, ou sedes urbanas mais importantes, quando a microrregião já adquiriu um complexo municipal mais numeroso; 2 a nos municípios do entorno dessas áreas, a área rural tende a desmembrar seus estabelecimentos, absorvendo, aparentemente, os pequenos produtores expulsos dos remembramentos do município central; 3. à medida que esse processo se desenvolve, a população rural que não tem terra - ocupantes, meeiros e posseiros - ou que viva de pequenas áreas de subsistência, vai-se concentrando, quase sempre provisoriamente, nas vilas e povoados e principalmente nas sedes dos municípios da microrregião; 4. quando os círculos concêntricos dos remembramentos de dois grupos de municípios estão muito próximos e tendem a tangenciar-se, as sedes dos municípios intermediários a ambos transformam-se em sedes transitórias das famílias migrantes, em geral, com os indicadores de crescimento urbano mais baixo da microrregião e altos índices de subnormalidade no padrão habitacional e no regime de coabitação e aluguéis.

A rigor, esse processo fica reproduzindo-se 
permanentemente e apresenta-se em vários estágios, segundo as microrregiões. Explica e determina os tipos, a estabilidade e os padrões dos assentamentos das populações de toda a região, tanto urbanas quanto rurais, bem como os níveis de pressão da demanda habitacional em determinadas cidades ou municípios

Esses níveis de pressão expressam-se por vários indicadores que, inclusive, revelam certas perspectivas a curto e médio prazo de intensificação maior ou menor da demanda habitacional nas sedes municipais por intermédio da tendência de esvaziamento presente na maioria das áreas rurais.

Um dos indicadores da pressão sobre as cidades da região, na década de 1970, é exatamente sua taxa de crescimento no período. Essas taxas tenderiam a incrementar-se ou arrefecer-se, segundo a presença de um excedente de famílias sem a propriedade dos estabelecimentos rurais locais e as tendências do remembramento e das condições da produção no setor primário no município e sua microrregião.

Levando em conta esses diferentes estágios e trabalhando com estimativas otimistas do número de estabelecimentos rurais ter aumentado de $10 \% \mathrm{em}$ cada microrregião, ainda teremos uma pressão eminente sobre as cidades, da ordem de $51,8 \%$ da população que atualmente ainda reside na área rural dispersa da região, ou seja, haveria provavelmente um afluxo para as áreas urbanas da ordem de $51,8 \%$ dos atuais 439.770 habitantes da àrea rural dispersa, ouseja 44.056 famílias de nivel de renda familiar provável abaixo de um salário mínimo, demandando às sedes de municípios ou aos aglomerados rurais.

Fica assim definida uma perspectiva que somente não se concretizará se houver condições de absorção da população citada por regimes alternativos de trabalho no campo.

Essa realidade concreta ilustra claramente a dinâmica da distribuição e da redistribuição dessas populações nos diferentes assentamentos urbanos e rurais, submetidas às formas que toma a organização da produção no espaço regional.

Tal evidência também altera a concepção, ou a formulação, do objeto do planejamento urbano, ampliando seu âmbito geográfico, acumulando novas variáveis e enfraquecendo a especificidade do urbano como objeto de análise e intervenção isolado.

Um último equívoco que interfere na validade e na eficácia do planejamento urbano, refere-se:

1.) a uma postura neutra em face dos processos políticos (decisórios), que advêm dos próprios objetivos do planejamento quando se propõe, en- quanto uma prática sistematizada, a oferecer 'alternativas' de solução (técnica) ao processo decisório com a intenção de deixá-lo livre para a decisão final.

2.) a um comportamento tecnocrático que produz análises e proposições, como uma atividade alienada dos componentes da realidade estudada e dirigida somente ao poder governamental, resultando uma preocupação bem maior com a elaboração de documentos de análise e propostas do que com as condições de sua implementação.

O conhecimento do processo da evolucão concreta de cada espaço habitado, ou melhor, sua formulação, deve ser um 'conhecimento comprometido' com a intervenção sobre aquele processo com o objetivo de alterá-lo. Esse compromisso inclui algumas novas relações, importantes no quadro do conhecimento do objeto do planejamento por seu compromisso com uma ação prática determinada e dependente de fatores aparentemente externos ao processo de produção do espaço habitado

A definição do objeto do planejamento do espaço habitado como sendo o processo de produção e reprodução do quadro físico-espacial dos assentamentos humanos (urbanos e rurais) vai gerar proposições de intervenção mais realistas e eficientes, mas também de implementação mais complicada. Se, por um lado, mesmo enquanto planejamento de gabinete, é mais difícil descobrir de que modo controlar um processo de produção do espaço habitado, por outro, é inerente à ação prática do planejamento - que esse controle subentende - uma ação política que vai envolver o conhecimento do próprio objeto em uma dimensão social mais completa.

Essa ação política indispensável inclui a população enquanto usuária do espaço habitado, como participante do processo que decide sobre seu espaço. Essa participação só é válida quando a população também 'conhece', exercita, com os planejadores, o entendimento do processo de produção de seu espaço, transformando esse conhecimento em força real de pressão para sua mudança.

A rigor, o conhecimento do processo de produção do espaço habitado (ou seja, a formulação correta dos problemas dos assentamentos humanos) já contém ou deixa inferir as forças de natureza política. O que falta é a democratização desse conhecimento, não apenas pelas divulgações de fórmulas acabadas mas como um processo partilhado na formulação dos diagnósticos e das propostas de solução. Partilhado quer dizer produzido em conjunto, não como uma estratégia de engajamento da população mas como assunção de uma forma correta de tratar um fenômeno particular; como um método que admite que conhecimento é poder e que povo 
consciente é o gérmen do melhor poder. A consciência da população se faz pela força da produção conjunta do conhecimento de seus próprios problemas. 